\title{
A rare case of unicornuate uterus with non-communicating rudimentary horn containing functional endometrium
}

\author{
Priyanka*, Harbhajan Shergill, Romi Bansal, Mohini Aggarwal
}

Department of Obstetrics and Gynecology, Adesh Institute of Medical Science and Research, Bathinda, Punjab, India

Received: 28 September 2018

Accepted: 22 October 2018

\section{*Correspondence:}

Dr. Priyanka,

E-mail: priyanka.garg.u@gmail.com

Copyright: (C) the author(s), publisher and licensee Medip Academy. This is an open-access article distributed under the terms of the Creative Commons Attribution Non-Commercial License, which permits unrestricted non-commercial use, distribution, and reproduction in any medium, provided the original work is properly cited.

\begin{abstract}
Unicornuate uterus with rudimentary horn is a rare type of anomaly. The incidence is approximately 1/100,000. Mullerian anomalies are associated with many obstetrical and gynecological complications. Non-communicating and functional rudimentary horn can cause severe pain in abdomen due to accumulation of the blood causing its distension. Authors report a case of 25 years old patient with unicornuate uterus with non-communicating rudimentary horn containing functional endometrium presenting with chief complaints of severe pain in lower abdomen associated with multiple episodes of vomiting.
\end{abstract}

Keywords: Dysmenorrhoea, Mullerian anomalies, Rudimentary horn, Unicornuate uterus

\section{INTRODUCTION}

Mullerian duct anomalies are seen very rarely. Unicornuate uterus with rudimentary horn is a rare type of anomaly due to defective fusion of malformed duct with contralateral duct. ${ }^{1}$

The incidence is approximately $1 / 100,000$. It is usually diagnosed incidentally, or patient may present with gynecological and obstetrical complications like dysmenorrhea, dyspareunia, chronic pelvic pain or with acute abdomen following distension and rupture of noncommunicating rudimentary horn. Ectopic pregnancy can occur in non-communicating rudimentary horn and its incidence is between $1 / 100,000$ to $1 / 40,000$ pregnancies. ${ }^{2}$,

\section{CASE REPORT}

Authors report a case of 25 years old, P1L1 admitted to emergency ward of Adesh Medical College, Bathinda with chief complaints of severe pain in lower abdomen associated with multiple episodes of vomiting.

She attained menarche at 13 years of age and had severe dysmenorrhea since then. Her menstrual cycle was of 40 days and bleeding lasted for 3 to 4 days with normal amount. She was diagnosed with some uterine abnormality two years back when she got pregnant. She underwent preterm vaginal delivery at 8 months giving birth to a female baby weighing $1.5 \mathrm{~kg}$.

\section{Examination}

On general examination her blood pressure was 130/80 $\mathrm{mm} \mathrm{Hg}$ with heart rate of 102 beats/min. Her secondary sexual characters were well developed.

$P / A$

Vague firm mass of approximately 14 weeks felt in the suprapubic region, tender with restricted mobility. 


\section{$P / S$}

Cervix and vagina healthy.

$P / V$

Firm tender mass of 14 weeks size felt deviated towards right fornix, left fornix free.

\section{Investigations}

$\mathrm{Hb}-8 \mathrm{gm} \%$

Platelet count-2.4 lakhs

BT-3'20',

CT-5'10,

INR PTI-1.21

TSH-2.52

CA125-91.1

\section{LFT-WNL}

RFT-WNL

\section{$\mathrm{Na} / \mathrm{K}-140 / 3.5$}

Echocardiography-Large $2.4 \mathrm{~cm}$ ostium secundum ASD with left to right shunt with LVEF of 58\%

IVP-Right renal agenesis with left sided duplex kidney with partially duplicated pelvicalyceal system

USG-Small unicornuate uterus of $4.8 \times 4.3 \times 2.6 \mathrm{~cm}$ with right adnexal mass lesion of $14.3 \times 7.9 \mathrm{~cm}$ likely suggestive of endometrioma, endometrial thickness $6.1 \mathrm{~mm}$, right renal agenesis with hypertrophied left kidney with duplex system.

MRI-Evidence of two separate horns-one of the horn/primary horn, $8.6 \times 2.5 \mathrm{~cm}$ is located towards left of midline which is communicating with cervical and vaginal cavity. Other bilobed rudimentary horn located towards right and extending towards left of midline. It shows intrauterine fluid collection of $19 \times 6.5 \mathrm{~cm}$ which shows hyperintense signal intensity on T1W1 and T2W1 consistent with hematometra. Its wall thickness measures $7.5 \mathrm{~mm}$. Right ovary seen anterior to bilobed horn and left ovary appears unremarkable. Right renal agenesis with left renal duplex kidney.

Patient was given two units of blood transfusion and after proper fitness from cardiologist (due to ASD) and anesthetist, patient was taken up for exploratory laparotomy.

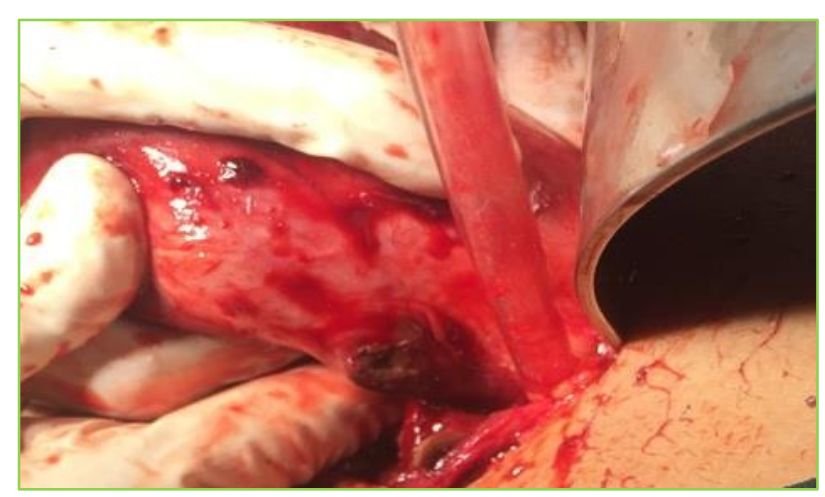

Figure 1: Rudimentary horn with rent on posterior surface.

Intraoperative findings- $10 \times 8 \mathrm{~cm}$ non- communicating rudimentary horn with small rent posteriorly (Figure 1), containing hematometra was present on right side. The right tube and ovary were embedded in the rudimentary horn (Figure 2).

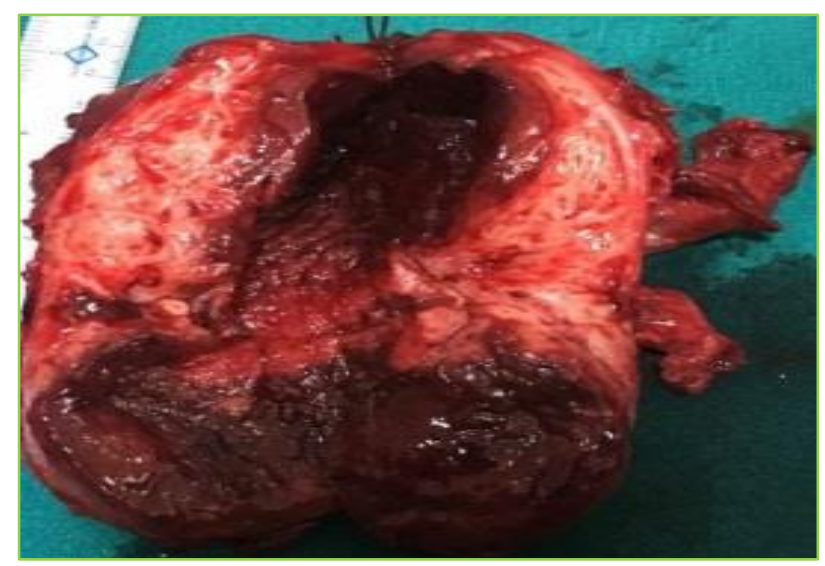

Figure 2: Cut section of excised rudimentary horn with embedded tube and ovary.

The rudimentary horn was adherent to the adjacent gut and omentum and numerous aberrant blood vessels were attached to it. On further inspection, small size uterus with left sided tube and ovary were present near left lateral pelvic wall (Figure 3).

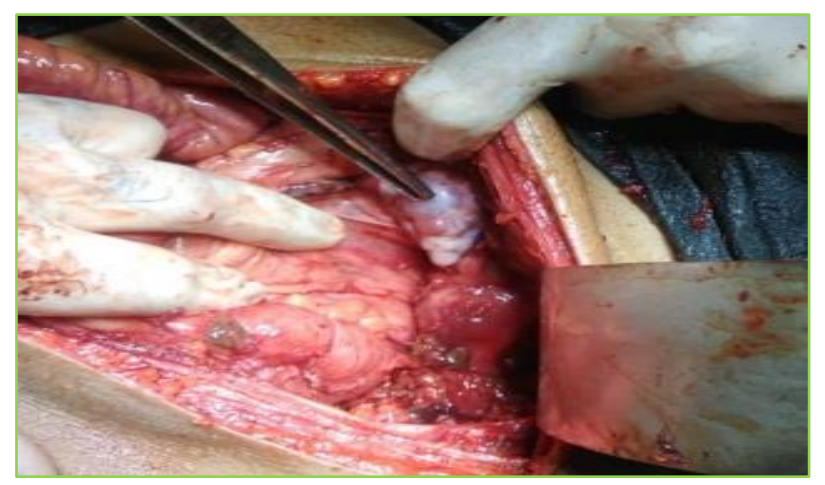

Figure 3: Uterus and left sided ovary. 
Gut was malrotated with caecum on left side. Meckel's diverticulum was also present. Left sided ureter delineated, right sided ureter was absent. The rudimentary horn was excised after separating it from surrounding structures. No endometriotric lesions were found in the pelvis. The specimen was sent for histopathological examination which revealed uterine rudimentary horn $(9 \times 3 \mathrm{~cm})$ with functional endometrium with hematometra with one sided fallopian tube $(4 \mathrm{~cm})$ and ovary $(2 \times 1.5 \mathrm{~cm})$. Patient was discharged on 7 th postoperative day in satisfactory condition.

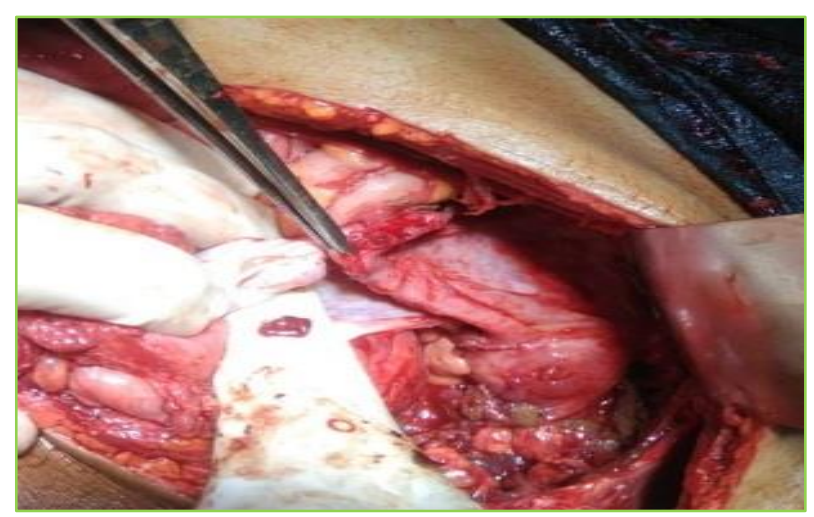

Figure 4: Uterus and left sided fallopian tube.

\section{DISCUSSION}

Normally the fusion of two Mullerian ducts occurs to form the uterus, fallopian tube, cervix and proximal twothird of vagina. ${ }^{4}$ Abnormal formation, fusion or resorption of the Mullerian ducts during embryogenesis results in the development of Mullerian duct anomalies. These are estimated to occur in $0.1-0.5 \%$ of women. Defective formation of malformed duct with contralateral duct results in unicornuate uterus with rudimentary horn. Rudimentary horn may consist of a functional or nonfunctional endometrium. It can be communicating or non-communicating but in $80-90 \%$ of cases it is noncommunicating. Women with this anomaly are susceptible to many obstetric and gynecological complications like infertility, endometriosis, dysmenorrhea, hematometra, frequent first trimester abortions, malpresentation and preterm labour. Noncommunicating and functional rudimentary horn can cause severe pain in abdomen due to the hematometra as seen in present case.

\section{Classification of anomalies}

Many classifications of uterine anomalies exist; for instance, the American Fertility Society (AFS) classification, the modified AFS classification by Rock and Adam and the Buttramand Gibbons classification. ${ }^{5-8}$

Mullerian duct anomalies are categorized most commonly into 7 classes according to the American
Fertility Society (AFS). The classification scheme in an abbreviated form is as follows:

\section{Class I (hypoplasia/ agenesis)}

This class includes uterine/cervical agenesis or hypoplasia.

\section{Class II (unicornuate uterus)}

The unicornuate uterus results complete/almost complete, arrest of development of the Mullerian duct. If the arrest is incomplete, a rudimentary horn with/without functioning endometrium is present. If the rudimentary horn is obstructed, it may present as an enlarging pelvic mass. If the contralateral horn is healthy and well developed, a full-term pregnancy can occur.

\section{Class III (didelphys uterus)}

This anomaly results from complete non-fusion of both Mullerian ducts. The individual horns are fully developed, and cervices are inevitably present.

\section{Class IV (bicornuate uterus)}

A bicornuate uterus results from partial non-fusion of the Mullerian ducts. The central myometrium may extend to the level of the internal os (bicornuate unicollis) or external os (bicornuate bicollis).

\section{Class V(septate uterus)}

A septate uterus results from failure of resorption of the septum between the 2 uterine horns (septum can be partial or complete). Differentiation between a septate and a bicornuate uterus is important because the management differs.

\section{Class VI (arcuate uterus)}

An arcuate uterus has a single uterine cavity with a convex or flat uterine fundus, the endometrial cavity, which demonstrates a small fundal cleft or impression with a flat outer.

\section{Class VII (diethylstilbestrol-related anomaly)}

The uterine anomaly is seen in the female offspring of as many as $15 \%$ of women exposed to DES during pregnancy. Female fetuses who are affected have a variety of abnormal findings that include uterine hypoplasia and a T-shaped uterine cavity.

The modified AFS classification by Rock and Adam: this classification correlates anatomic anomalies with embryologic arrests. Thus, uterovaginal anomalies are categorized as dysgenesis disorders or vertical or lateral fusion defects. 
There is a further subdivision into obstructive or nonobstructive forms. Immediate treatment is not needed for nonobstructive forms, but obstructive uterovaginal anomalies require immediate treatment because of retrograde flow of trapped fluids with increasing pressure on surrounding organs.

\section{Class 1}

Dysgenesis of Mullerian ducts. This class includes agenesis or hypoplasia of the Mullerian duct derivatives (the uterus and upper two-thirds of the vagina).

\section{Class 2}

Disorders of vertical fusion. There is failure of fusion of the Mullerian system with the sino-vaginal bulb (cervical dysgenesis and obstructive and nonobstructive transverse vaginal septa).

\section{Class 3}

Disorders of lateral fusion. This class of anomalies comprises of a duplicated or partially duplicated reproductive tract. The disorders are due to impaired fusion and/or septal resorption of fusing Mullerian ducts attempting to form the uterus, cervix, and upper vagina. It includes anomalies due to failure of fusion of the paired Mullerian ducts (as in didelphic and bicornuate uteri) and failure of midline septum resorption after fusion (as in septate uterus). Disorders due to lateral fusion defects are further subclassified into: (a) the symmetric nonobstructive form (unicornuate, bicornuate, didelphic, septate, and DES-related uteri); (b) the asymmetric obstructive form (unicornuate uterus with obstructed horn, double uterus with unilaterally obstructed horn, and double uterus with unilaterally obstructed vagina).

\section{Class 4}

Unusual configurations and combinations of defects.

According to American fertility society classification of the Mullerian anomalies, our patient belongs to class II or class 3 of the modified AFS classification by Rock and Adam having unicornuate uterus with noncommunicating rudimentary horn with functional endometrium. She had history of preterm delivery in the past. Now she presented with severe pain abdomen which was due to hematometra distending the rudimentary horn and its rupture due to very thin myometrial tissue. Strong relationship exists between the Mullerian duct anomalies and renal anomalies. ${ }^{9,10}$ Renal anomalies are detected in $30-40 \%$ of women with uterine anomalies. ${ }^{11,12}$ Most of them are detected incidentally during routine imaging. Absence of one kidney and duplex collecting system has been the most common congenital renal tract abnormalities associated with obstructive uterovaginal anomalies. ${ }^{13-16}$ These similar findings were reported in present case. Imaging helps in early diagnosis of these anomalies. The first baseline investigation is sonographic examination. However, on the basis of negative ultrasound findings Mullerian duct anomalies cannot be excluded. MRI has proven to be standard imaging technique with high rate of diagnostic accuracy for Mullerian abnormalities. It provides high resolution images of uterine body, fundus, and cervix and can assess the urinary tract anomalies also. Once the diagnosis is made, the horn should always be excised along with the adjacent tube.

\section{CONCLUSION}

Unicornuate uterus with non-communicating rudimentary horn is a rare condition. But whenever diagnosed in younger women in the reproductive age group, noncommunicating rudimentary horn containing functional endometrium must be excised by expert surgeon either laparoscopically or by laparotomy. Evaluation of renal system should always be done due to high incidence of associated urological anomalies.

\section{Funding: No funding sources \\ Conflict of interest: None declared \\ Ethical approval: Not required}

\section{REFERENCES}

1. Crosby WM, Hill EC. Embryology of the Mullerian duct system. Review of present day theory. Obstet Gynecol. 1962;20:507-15.

2. Johansen K. Pregnancy in a rudimentary horn: Two case reports. Obstet Gynecol. 1969;34:805-8.

3. O'Leary JL, O'Leary JA. Rudimentary horn pregnancy. Obstet Gynecol. 1963;22:371-5.

4. Troiano RN, McCarthy SM. Mullerian duct anomalies: imaging and clinical issues. Radiol. 2004;233(1):19-34.

5. Syed I, Hussain HK, Weadock W, Ellis J. Uterus, Mullerian duct abnormalities. In: Eugene CL, ed. eMedicine > Radiology > Obstetrics/ Gynecology; 2009.

6. AFS. The American Fertility Society classifications of adnexal adhesions, distal tubal occlusion, tubal occlusion secondary to tubal ligation, tubal pregnancies, Mullerian anomalies and intrauterine adhesions. Fertil Steril. 1988;49(6):944e955.

7. Rock JA, Adam RA. Surgery to repair disorders of development In: Nichols DH, Clarke-Pearson, eds. Gynecologic, Obstetric, an Related Surgery. $2^{\text {nd }}$ ed. St. Louis, MO: Mosby-Year Book; 2000:780-813.

8. Buttram VC, Gibbons WE. Mullerian anomalies: a proposed classification (an analysis of 144 cases). Fertil Steril. 1979;32:40-8.

9. Marshall FF, Beisel DS. The association of the uterine and renal anomalies. Obstet Gynecol. 1978;51:559-62.

10. Li S, Qayyum L, Coakley FV, Hricak H. Association of renal agenesis and Mullerian duct anomalies. J Comput Assist Tomogr. 2000;24:829-34. 
11. Fedele L, Bianchi S, Agnoli B, Tozzi L, Vignali M. Urinary tract anomalies associated with unicornuate uterus. Urol. 1996;155:847-8.

12. Oppelt PG, Lermann J, Strick R, Dittrich R, Strissel P, Rettig I, et al. Malformations in a cohort of 284 women with Mayer-Rokitansky-Küster-Hauser syndrome (MRKH). Reprod Biol Endocrinol. 2012;10:57-63.

13. Smith NA, Laufer MR. Obstructed hemivagina and ipsilateral renal anomaly (OHVIRA) syndrome: management and follow-up. Fertil Steril. 2007;87:918-22.

14. Fedele L, Motta F, Frontino G, Restelli E, Bianchi S. Double uterus with obstructed hemivagina and ipsilateral renal agenesis: pelvic anatomical variants in 87 cases. Hum Reprod. 2013;28:1580-3.
15. Gholoum S, Puligandla PS, Hui T, Su W, Quiros E, Laberge JM. Management and outcome of patients with combined vaginal septum, bifid uterus and ipsilateral renal agenesis (Herlyn-WernerWunderlich syndrome). J Pediatr Surg. 2006;41:98792.

16. Hartman GW, Hodson CJ. The duplex kidney and related abnormalities. Clin Radiol. 1969;20:387-400.

Cite this article as: Priyanka, Shergill H, Bansal R, Aggarwal M. A rare case of unicornuate uterus with non-communicating rudimentary horn containing functional endometrium. Int J Reprod Contracept Obstet Gynecol 2018;7:5182-6. 